\title{
Diagnostic yield of the analysis of the pattern of electrical activity of muscle and of individual motor unit potentials in neurogenic involvement
}

\author{
A. F U G L S A N G - F R E D E R I K S E N, U. S C H E E L, \\ A N D F. B U C H T H A L
}

From the Laboratory of Clinical Neurophysiology, Rigshospitalet, and Institute of Neurophysiology, University of Copenhagen, Denmark

SUMMARY The pattern of electrical activity and the properties of individual motor unit potentials were analysed in the flexor muscles of the forearm of 15 patients with motor neurone disease and 15 patients with a lesion of the brachial plexus. The best diagnostic yield from the pattern of electrical activity was obtained when the force was $30 \%$ of maximum: The number of spikes (turns/5 s) was diminished in $70 \%$ of the patients; none showed the increase in turns characteristic of myopathy. The decrease in the number of turns was often associated with an increased incidence of long time intervals between turns and with an increased amplitude between turns. The mean duration of individual motor unit potentials was prolonged in $78 \%$ of the patients; none showed the decrease in mean duration characteristic of myopathy. Prolongation of the mean duration of motor unit potentials produced by cooling of normal muscle, led to añ decrease in the number of turns. This suggested that the diminished number of turns in neurogenic involvement was due mainly to the prolonged duration of motor unit potentials.

Quantitation of the pattern of electrical activity has been used to distinguish between patients with myopathy and normal subjects. The criteria used were the number of spikes per $5 \mathrm{~s}$ ('turns'), the amplitude of the pattern (given as the amplitude between the spikes), and the distribution of time intervals between the spikes (Willison, 1964; Rose and Willison, 1967; Dowling et al., 1968). Fuglsang-Frederiksen et al. (1976) increased the diagnostic certainty of this procedure by using a force of $30 \%$ of maximum (Fuglsang-Frederiksen and Månsson (1975). In patients with neurogenic involvement, Hayward and Willison (1973) investigated the pattern of activity at a constant force $(2 \mathrm{~kg}-5 \mathrm{~kg})$ and, unlike in myopathy, they found the change in amplitude between turns and not a change in the number of turns to be the characteristic change of a neurogenic lesion.

The purpose of the study presented in this report was (1) to determine, at a force which was a fixed fraction of maximum, to what extent number of turns, amplitude between turns, ratio of turns to amplitude between turns, and distribution of time intervals between turns allowed identifica-

Accepted 29 November 1976 tion of a neurogenic lesion; (2) in neurogeniç lesions, to compare the diagnostic yield obtained? from the quantitation of the pattern of electrical activity and from the properties of individual motor unit potentials; (3) in model experiments, to evaluate the relative contribution to the number of turns of loss of motor units and of changes in the properties of motor unit potentials.

\section{Patients and methods}

The material comprised 15 patients with motor neurone disease (nine males and six females), and 15 patients with paresis secondary to a lesion of the brachial plexus (13 males and two females). The patients with motor neurone disease were 50 74 years old; nine of the patients with a lesion of the brachial plexus were more than 40 years, and six were 18-37 years old.

MAXIMUM FORCE OF THE FLEXOR MUSCLES OF THE FOREARM

The maximum force was measured at the wrist with the elbow joint at a right angle (FuglsangFrederiksen and Månsson, 1975). The normal force in males was $32 \mathrm{~kg}$, SD $5 \mathrm{~kg}$ (nine subjects); 
and in females $20 \mathrm{~kg}$, SD $2 \mathrm{~kg}$ (10 subjects). In five patients with motor neurone disease and in two with a lesion of the brachial plexus, the force was within the range of normal (diminished by less than $30 \%$, Fig. 1).

\section{QUANTITATION OF THE PATTERN OF ELECTRICAL ACTIVITY}

The pattern was recorded via concentric needle electrodes (DISA 13K32) in 10 different sites of the flexor muscles of the forearm (m. biceps brachii and $\mathrm{m}$. brachialis) at $30 \%$ of maximum force (Fuglsang-Frederiksen and Månsson, 1975). The number of turns per $5 \mathrm{~s}$, the mean amplitude between turns, the ratio of the number of turns to mean amplitude, the distribution of time intervals between turns, and the distribution of amplitudes between turns were determined as described by Fuglsang-Frederiksen and Månsson (1975) and Fuglsang-Frederiksen et al. (1976). After one to three recordings of $5 \mathrm{~s}$ the patients rested for one to two minutes. In addition, the pattern was analysed in 10 patients at a force of $10 \%$ of maximum, in six patients at near-maximum force, and in 17 patients at a constant force of $2 \mathrm{~kg}$. Findings in patients were compared with those in 30 subjects without history, symptoms, or signs of neuromuscular disease.

DIMINUTION IN TURNS ATTRIBUTABLE TO A DECREASE IN FORCE (LOSS OF MOTOR UNITS)

The number of turns per 5 seconds was determined in the brachial biceps and brachialis muscles at $10 \%, 20 \%$, and $30 \%$ of maximum force $(10$ subjects). At each fraction of maximum force the number of turns were taken as the average from turns recorded in different sites of the muscle.

THE EFFECT OF PROLONGED DURATION OF MOTOR UNIT POTENTIALS ON THE NUMBER OF TURNS

In two subjects the duration of motor unit potentials in the brachial biceps and brachialis muscles was prolonged by cooling the upper arm from an intramuscular temperature of $36^{\circ} \mathrm{C}$ to $28^{\circ} \mathrm{C}$. The temperature was measured with a thermocouple inserted into the muscle. When the low temperature was reached the ice bag above the brachial biceps muscle was removed, and three concentric electrodes were placed in the muscle. At 10 different electrode positions, two or three different motor unit potentials (in all 20-28 potentials), or the number of turns per $5 \mathrm{~s}$ (at $30 \%$ of maximum force), was recorded alternately. The remaining ice bags were then removed and, with the three electrodes still in the same positions, the number of turns was determined for each increase in intramuscular temperature of $0.5^{\circ} \mathrm{C}$. Findings at $28^{\circ} \mathrm{C}$ were compared with those at $36^{\circ} \mathrm{C}$.

\section{THRESHOLDS OF VOLTAGE SHIFTS}

Removal of background activity by increasing the threshold of voltage shifts from 100 to $1000 \mu \mathrm{V}$ did not increase the diagnostic yield in eight patients with a neurogenic lesion (compared with findings in five controls). The diminution in the number of turns was as obvious with a threshold of $100 \mu \mathrm{V}$ as with a threshold of $500 \mu \mathrm{V}$ and $1000 \mu \mathrm{V}$.

INDIVIDUAL MOTOR UNIT POTENTIALS

Thirty-two to 42 different motor unit potentials were recorded during weak effort. The mean dura-

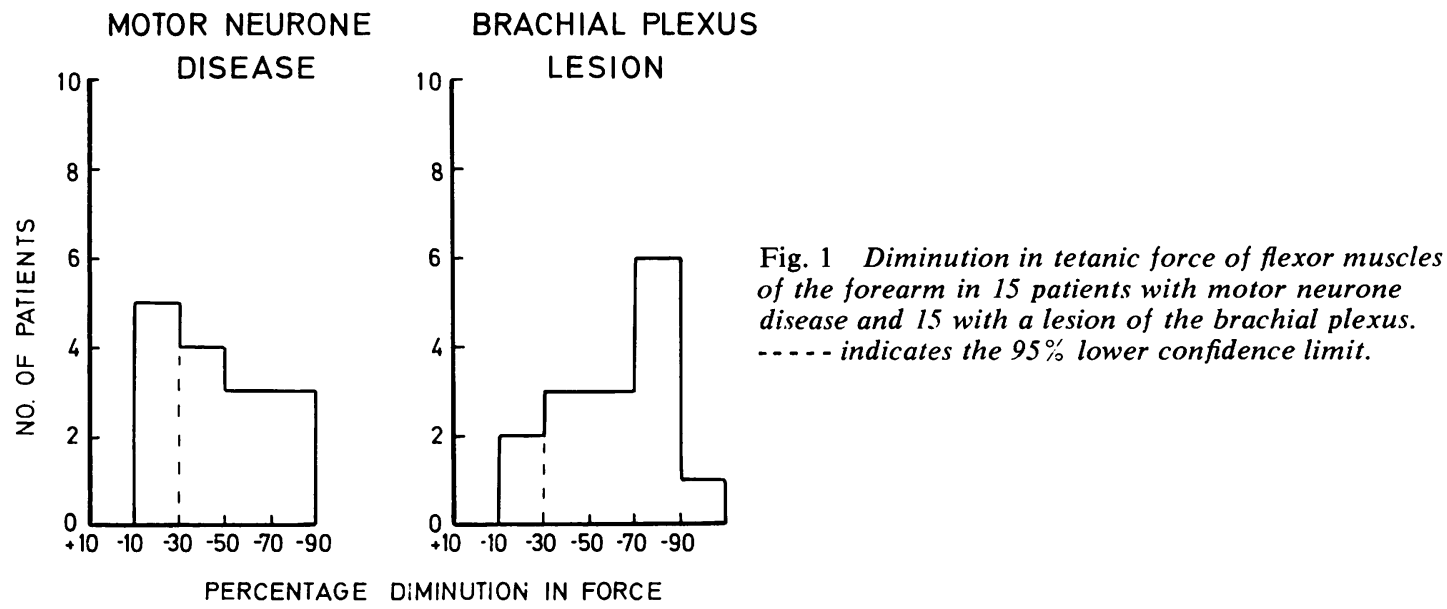


tion, the mean amplitude, and the incidence of polyphasic potentials were determined as described by Buchthal (1957). In addition, the pattern of electrical activity was recorded during full effort, and graded as 'discrete activity', 'reduced recruitment', and 'normal recruitment'.

\section{Results}

PATTERN OF ACTIVITY IN PATIENTS WITH WEAKNESS IN THE FLEXOR MUSCLES OF THE FOREARM SECONDARY TO A LESION OF THE BRACHIAL PLEXUS OR TO A MOTOR NEURONE DISEASE

Turns per $5 \mathrm{~s}$ at $30 \%$ of maximum force A diminished number of turns per $5 \mathrm{~s}$ identified $70 \%$ of 23 patients irrespective of whether the weakness was secondary to a lesion of the brachial plexus or to motor neurone disease (Fig. 2). In patients with motor neurone disease the decrease in turns was the more pronounced the lower the force, suggesting that the number of turns decreased as the disease progressed (Fig. 3).

\section{Time intervals between turns}

The incidence of long time intervals between turns was increased (Fig. 2). This incidence was measured as the ratio of intervals of more than $1.5 \mathrm{~ms}$ in duration to intervals of more than $0.75 \mathrm{~ms}(\Delta \mathrm{t})$. Time intervals of less than $0.75 \mathrm{~ms}$ were omitted to make sure that the initial peak of short time intervals did not obscure an increase in long time intervals (Fig. 4). All except two of the patients with a diminished number of turns had
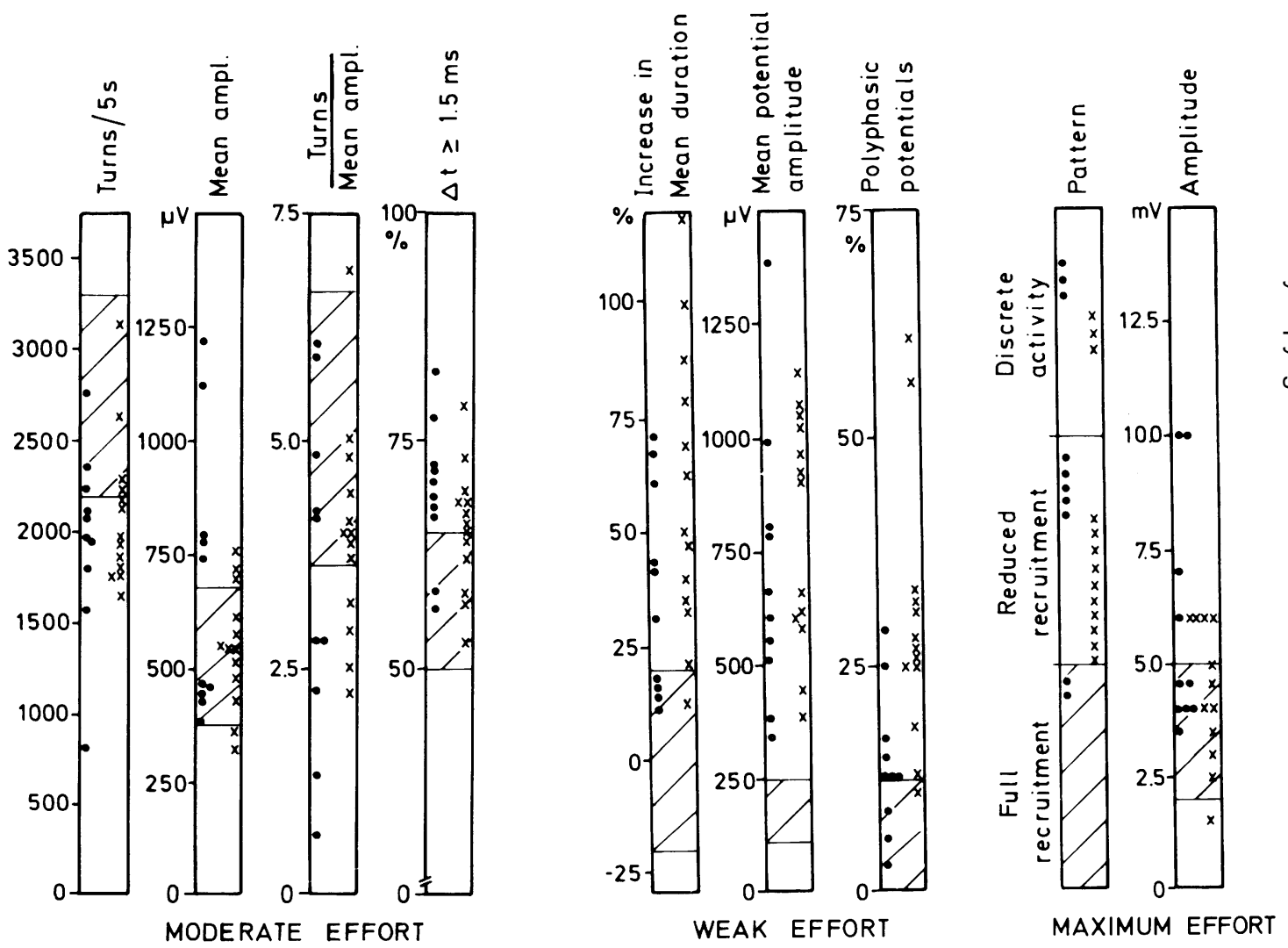

Fig. 2 Diagnostic yield of the different electromyographic criteria of abnormality in patients with weakness of the brachial biceps muscle secondary to a neurogenic lesion. Moderate effort: properties of the pattern of recruitment at $30 \%$ of maximum force. Weak effort: properties of individual motor unit potentials. Increase in mean duration is given as percentage of average duration in age-matched controls. Maximum effort: pattern of recruitment and its amplitude. Hatched areas give $95 \%$ confidence limit of normal. $\bullet=10$ patients with motor neurone disease; $X=13$ patients with lesion of the brachial plexus. 

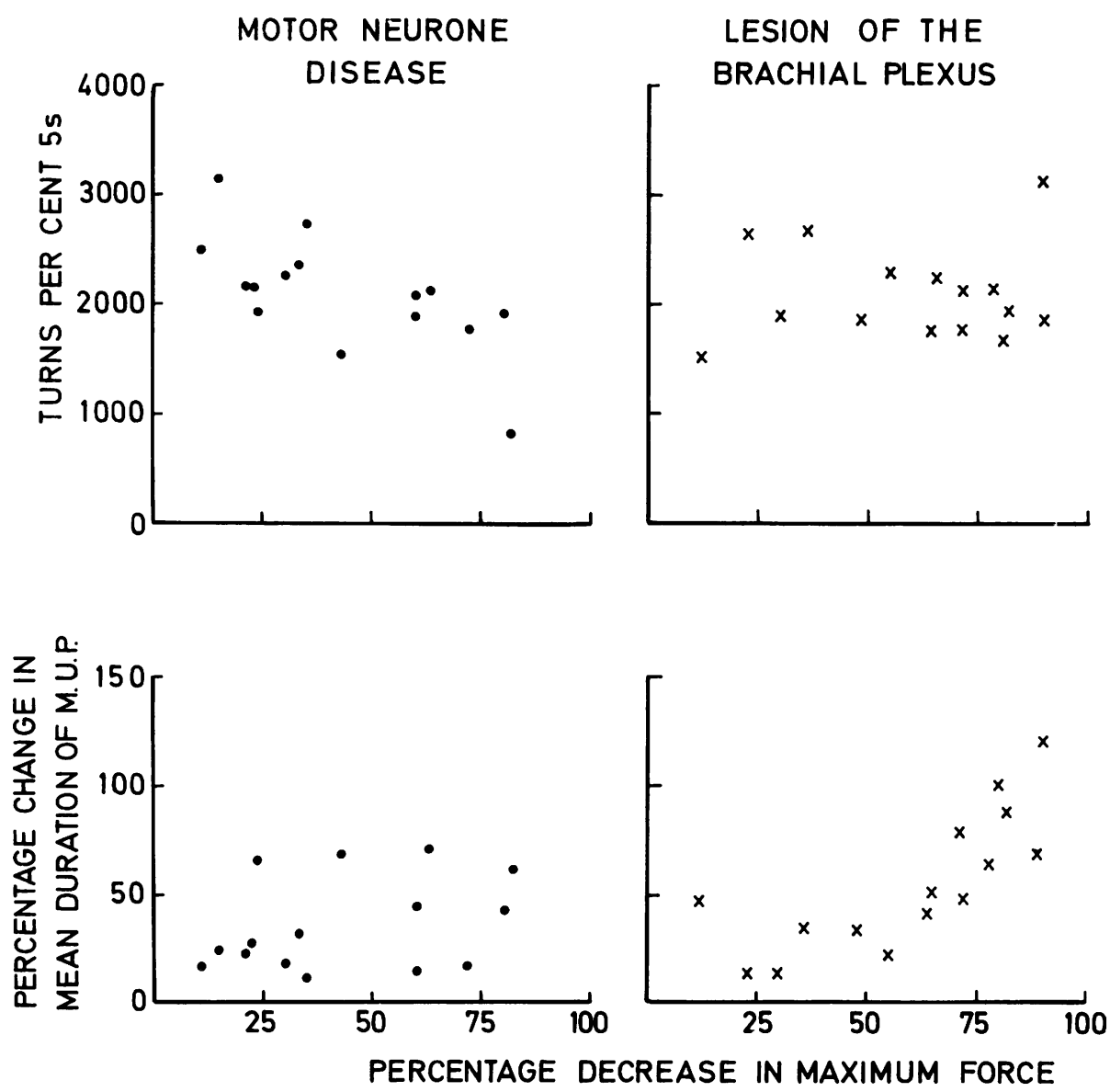

Fig. 3 Turns per $5 s$ (above) and increase in mean duration of motor unit potentials (below) as a function of the diminution in maximum force. Left-15 patients with motor neurone disease, right-15 patients with lesion of the brachial plexus. In motor neurone disease the number of turns per $5 s$ was: $-15 \times$ maximum force (percentage decrease) $+2750 ; S D$ 380; $P<0.01$. In lesions of the brachial plexus: the percentage change in duration of motor unit potentials was $1.0 \times$ maximum force (percentage decrease) -4 ; $S D$ 20; $P<0.001$.

an increased incidence of long time intervals. In one patient an increase in the incidence of long time intervals was the only sign of neurogenic involvement.

\section{Amplitude between turns}

The amplitude between turns was increased in eight of 23 patients and decreased in two patients (Fig. 2). An increase in amplitude identified two of the patients who had a normal number of turns and of time intervals between turns. The ratio of turns to amplitude and the relative incidence of small $(<0.5 \mathrm{mV})$ and of large $(>1 \mathrm{mV})$ amplitudes did not add information beyond that obtained from the mean amplitude between turns.
PATTERN OF ACTIVITY IN PATIENTS WITH NORMAL FORCE

Four of seven patients had a diminution in turns and one patient had only an increase in amplitude between turns.

TURNS AND AMPLITUDE AT DIFFERENT LOADS A diminished number of turns was more often observed with $30 \%$ of maximum force than with the following forces tested: maximum effort, $10 \%$ of maximum effort, 2 kilograms, 2 kilograms corrected for maximum force. In all 16 patients tested the number of turns was normal when the force was 2 kilograms (Fig. 5). The cause of the different diagnostic yield at different force was 

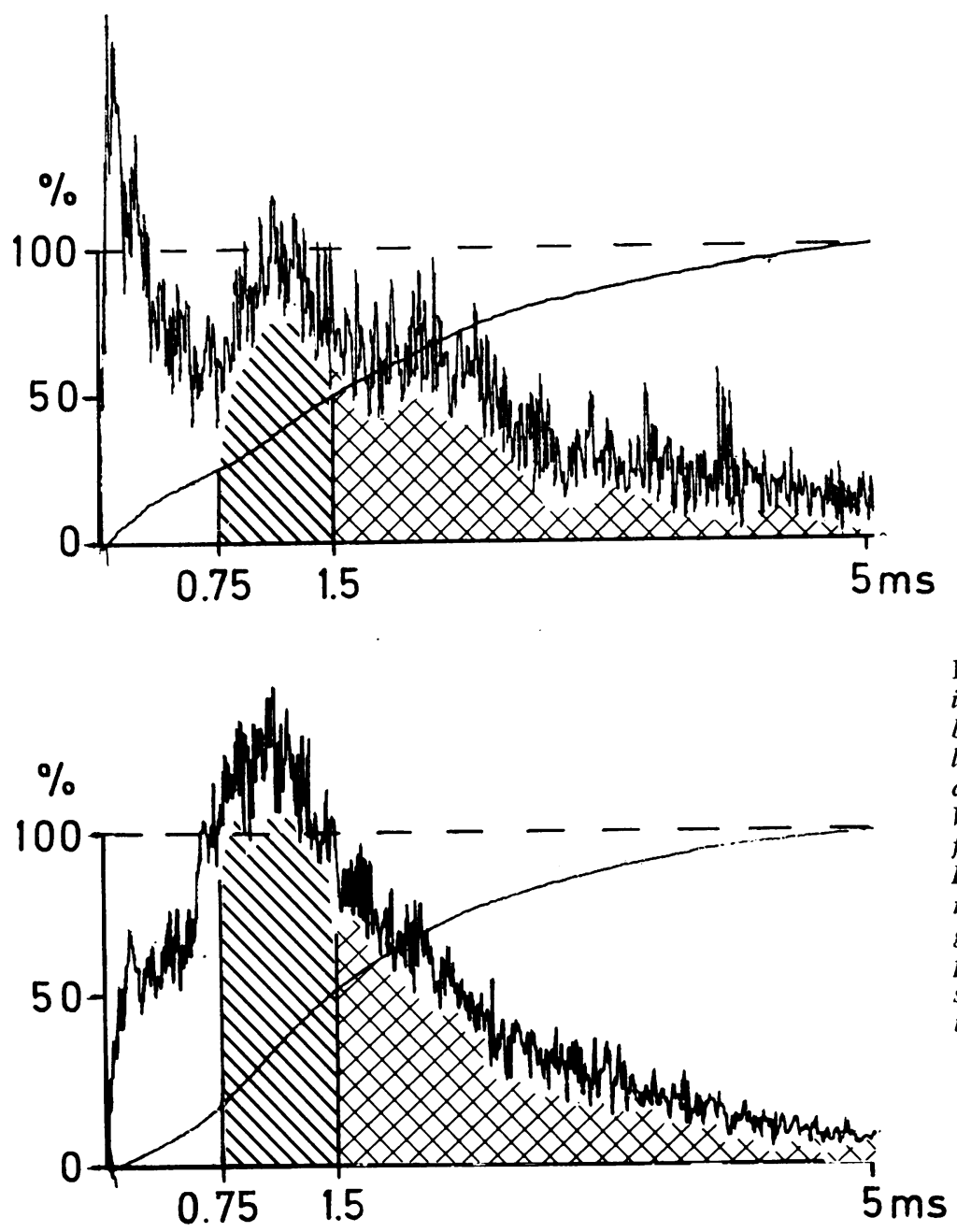

Fig. 4 Distribution of time intervals between turns in the brachial biceps of a patient with a lesion of the brachial plexus (above) and a normal subject (below). Vertical scale: cumulative frequency in per cent (full line). Horizontal scale: time categories in $m s$. The double hatched area is given in per cent of the hatched plus the double hatched area to show the displacement to longer time intervals in the patient.

disclosed when the number of turns was determined during a gradual increase in force from zero to maximum (Fig. 6). In patients with neurogenic involvement the slope of the increase in turns was lower than normal, resulting in the greatest difference between paretic and normal muscle when the force was $30-50 \%$ of maximum. Moreover, in normal muscle the number of turns decreased when the force exceeded $75 \%$ of maximum. When the force was $30 \%$ of maximum the amplitude between turns gave little additional information to that obtained from turns. Only when the force was 2 kilograms did mean amplitude afford information that was not obtained from the recording of the number of turns (in $40 \%$ of the patients).

SPECIFICITY OF THE PATTERN OF ACTIVITY TO DISTINGUISH NEUROGENIC FROM MYOGENIC INVOLVEMENT

None of the patients with neurogenic involvement showed the increase in turns that characterised myopathy. Conversely, $22 \%$ of 41 patients with myopathy showed a diminution in turns. Half of them were, nevertheless, characterised as having myopathy by an increase in the ratio of turns to mean amplitude (Fuglsang-Frederiksen et al., 1976). In one patient an increase in the ratio of 


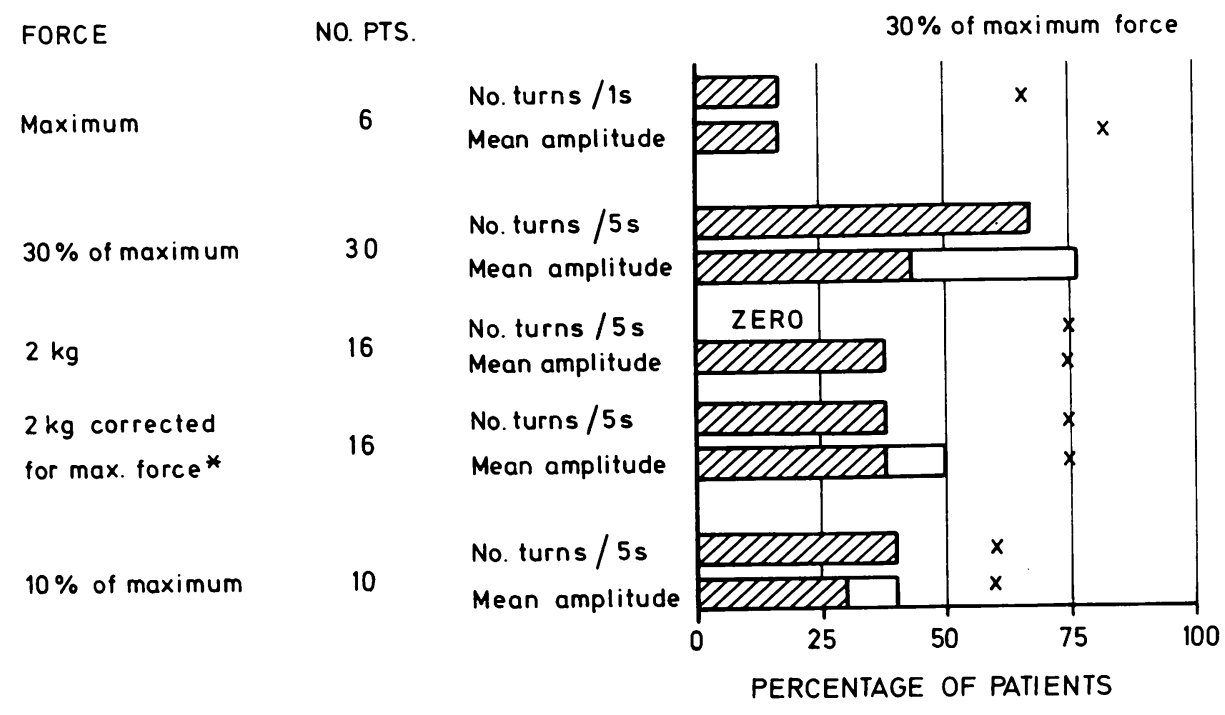

* Corresponding to $18 \pm 9 \%$ of maximum

Fig. 5 Cumulative diagnostic yield of number of turns and mean amplitude between turns at different force in patients with neurogenic involvement ( $m$. biceps brachii and $m$. brachialis); $X=$ diagnostic yield when the force was $30 \%$ of maximum; hatched area gives diagnostic yield of each criterion.

turns to mean amplitude simulated myopathy (Table).

INDIVIDUAL MOTOR UNIT POTENTIALS IN PATIENTS WITH DIMINISHED FORCE

The increase in duration of motor unit potentials identified 18 of 23 patients $(78 \%)$ as having neurogenic involvement (Fig. 2). All except four of these patients also had a diminished number of turns. In patients with a lesion of the brachial plexus the prolongation in duration of motor unit potentials was the more marked, the more advanced the lesion (Fig. 3). In all patients the average amplitude of individual motor unit potentials was increased. Two patients, with normal mean duration, had an increase in the incidence of polyphasic potentials. The increase in the incidence of polyphasic potentials $(10 \%$ $40 \%$ of all potentials) was not related to the decrease in turns.

The increase in amplitude and in the incidence of polyphasic potentials are less specific parameters of abnormality because four of 41 patients with myopathy showed an increase in mean amplitude, and 29 showed an increase in the incidence of polyphasic potentials (Table) (FuglsangFrederiksen et al., 1976). None of the patients had the diminished mean duration that characterises myopathy (Table).
Finally, six patients had a pattern of discrete activity during full effort, and 15 had a reduced recruitment pattern. In these latter the criteria of the pattern obtained at $30 \%$ of maximum force identified 13 as having neurogenic involvement. The pattern of activity during full effort identified four patients who had a normal mean duration of motor unit potentials.

\section{PROPERTIES OF MOTOR UNIT POTENTIALS IN} PATIENTS WITH NORMAL FORCE

Five of seven patients had a prolonged mean duration, and all seven had an increased mean amplitude of motor unit potentials.

RECRUITMENT PATTERN DURING MAXIMUM EFFORT The more the pattern of recruitment was reduced, the more marked was the increase in mean duration, and in mean amplitude of motor unit potentials (Fig. 7). Similarly, the number of turns was diminished and the amplitude between turns increased.

FACTORS DETERMINING THE NUMBER OF TURNS The number of turns at $30 \%$ of maximum force depends on the total number of motor units and their firing frequency, the duration of individual motor unit potentials, their amplitude, the incidence of polyphasic potentials, and the degree of 


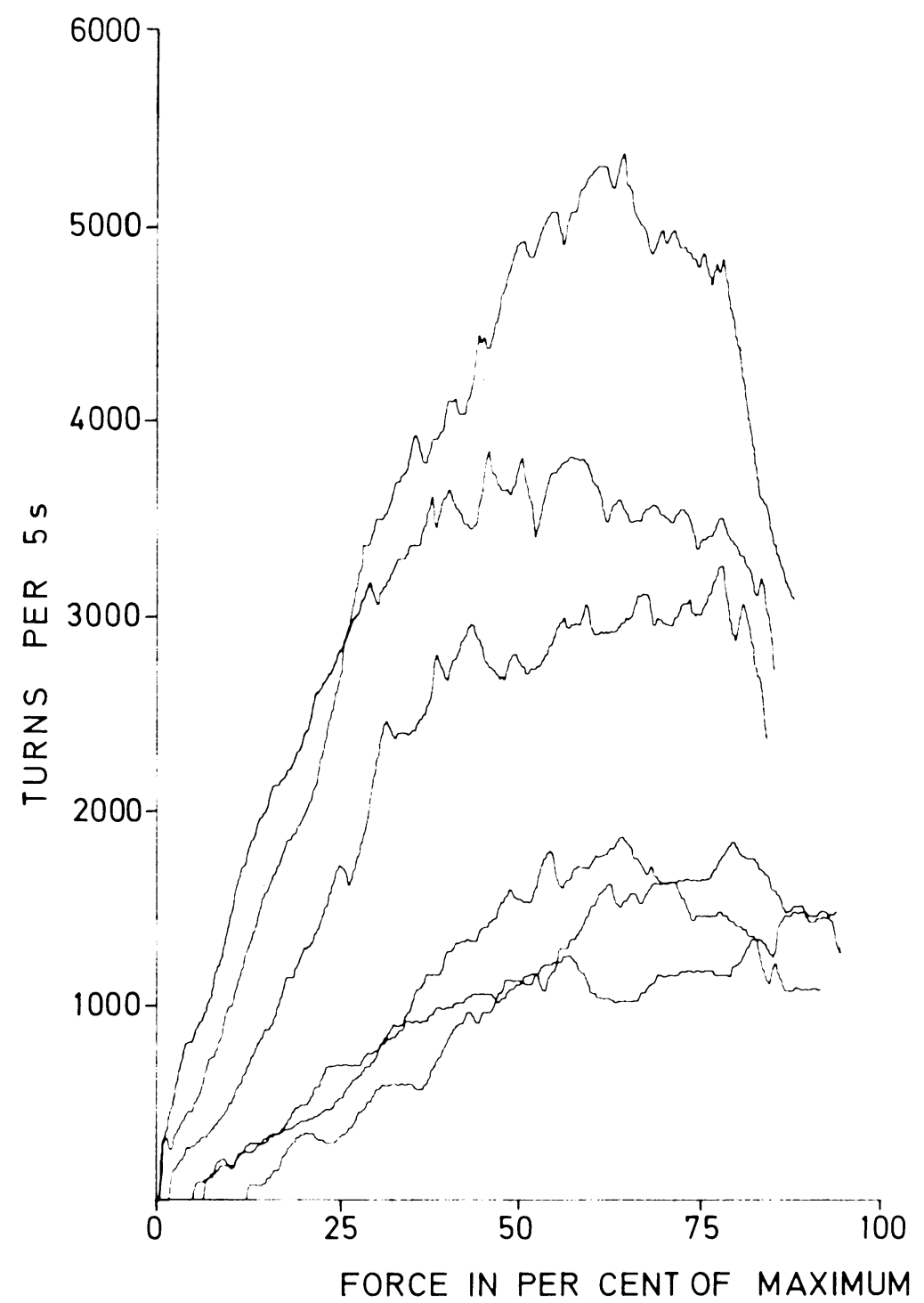

Fig. 6 Number of turns with continuously increasing force $(0-100 \%$, at constant rate, within $10 \mathrm{~s})$ in the brachial biceps muscle of a normal subject (three upper recordings) and of a patient with a lesion of the brachial plexus (three lower recordings). The number of turns were recorded for every $100 \mathrm{~ms}$ and converted to turns per 5 s.

synchronisation of the discharges of different motor units.

NUMBER OF MOTOR UNITS

The effect of loss of motor units on the number of turns was estimated from the decrease in the number of turns in normal subjects when the force was reduced from $30 \%$ to $10 \%$ of maximum (Fig.
8). Assuming that loss of motor units is randomly distributed among motor units independently of their threshold of recruitment, a reduction in the maximum force $\left(P_{0}\right)$ to one-third caused the number of turns at $30 \%$ of one-third of $P_{0}$ to be equal to the number of turns at $10 \%$ of $\mathrm{P}_{0}$. A decrease in maximum force of $67 \%$ corresponded to a decrease in turns of $39 \%(\mathrm{SD}=6)$. Thus, disregarding 
Table False positive criteria in the analysis of the pattern of activity and of individual motor unit potentials in patients with neurogenic involvement and myopathy

\begin{tabular}{|c|c|c|}
\hline & $\begin{array}{l}\text { False positive } \\
\text { criteria of } \\
\text { myopathy } \\
\text { (30 patients } \\
\text { with neuro- } \\
\text { genic involve- } \\
\text { ment) }\end{array}$ & $\begin{array}{l}\text { False positive } \\
\text { criteria of } \\
\text { neurogenic } \\
\text { involvement } \\
\text { (41 patients } \\
\text { with myopathy) }\end{array}$ \\
\hline Criteria & $\begin{array}{l}\text { Number of } \\
\text { patients }\end{array}$ & $\begin{array}{l}\text { Number of } \\
\text { patients }\end{array}$ \\
\hline $\begin{array}{c}\text { Number of turns per } 5 \mathrm{~s} \\
\text { turns }\end{array}$ & 0 increased & 9 decreased* \\
\hline Ratio $\overline{\text { mean amplitude }}$ & 1 increased & 1 decreased \\
\hline $\begin{array}{l}\text { Mean amplitude between turns } \\
\text { Time intervals } \leqslant 0.75 \mathrm{~ms} \\
\text { Time intervals } \geqslant 1.5 \mathrm{~ms} \\
\text { Duration of motor unit potentials } \\
\text { Incidence of polyphasic potentials } \\
\text { Amplitude of motor unit potentials }\end{array}$ & $\begin{array}{l}2 \text { decreased } \\
0 \text { increased } \\
0 \text { decreased } \\
0 \text { decreased } \\
22 \text { increased } \\
0 \text { decreased }\end{array}$ & $\begin{array}{l}0 \text { increased } \\
2 \text { decreased } \\
0 \text { increased } \\
1 \text { increased } \\
29 \text { increased } \\
4 \text { increased }\end{array}$ \\
\hline
\end{tabular}

the slight deviation from linearity, a decrease in maximum force of $10 \%$ corresponded to a decrease in the number of turns of $6 \%$.

\section{Duration of motor unit potentials}

To investigate the effect of a prolongation in the duration of motor unit potentials on the number of turns, the duration of motor unit potentials was increased by cooling the muscle. At $28^{\circ} \mathrm{C}$ the maximum force remained unaltered as compared with that exerted at $36^{\circ} \mathrm{C}$, and the number of turns at $30 \%$ of maximum force was diminished by $50 \%$. The mean duration was increased by $40 \%$, whereas the mean amplitude and the incidence of polyphasic potentials were unchanged. The number of turns increased linearly as the temperature increased from $28^{\circ} \mathrm{C}$ to $36^{\circ} \mathrm{C}$, as did the mean duration of motor unit potentials (Bentsen, 1945). Thus, an increase in duration of $10 \%$ corresponded to a decrease in turns of $12 \%$ $(\mathrm{SD}=2 \%)$.

\section{Amplitude of motor unit potentials}

An increase in amplitude of motor unit potentials can both increase and decrease the number of turns. It has not been possible to isolate its effect, but the increased amplitude might account for some of the scatter in the relationship between turns and, for example, the incidence of polyphasic potentials (Fig. 9).

Incidence of polyphasic potentials

In patients with a decrease in force secondary to a lesion of the brachial plexus we have estimated the number of turns to be expected from the decrease in force and from the increase in mean duration. The difference between observed and expected number of turns increased with an increasing incidence of polyphasic potentials at weak effort (Fig. 9). Thus an increase in the incidence of polyphasic potentials from, for example, $10 \%$ to $20 \%$ corresponded with an increase in turns of $24 \%(\mathrm{SD}=7 \%)$.

\section{Synchronisation between different motor units}

This was similar in paresis secondary to a lesion of the brachial plexus to that in normal muscle (Buchthal and Madsen, 1950). In motor neurone disease the difference between the observed and the expected number of turns was not related to the incidence of polyphasic potentials, probably because synchronisation between discharges of different motor units outweighed the increase to be expected from the increased incidence of polyphasic potentials.

\section{Discussion}

In $70 \%$ of the patients with neurogenic involvement the number of turns per $5 \mathrm{~s}$ was diminished when the force was $30 \%$ of maximum. By contrast, when the force was $2 \mathrm{~kg}$, the number of turns was within the $95 \%$ confidence limits of normal. This difference is due to the fact that the number of motor units activated at a constant load depends on the maximum force: a weak muscle needs to activate more motor units to carry a load of $2 \mathrm{~kg}$ than a strong muscle. Hence, in a weak muscle the diminution in the number of turns that characterises neurogenic involvement was obscured by the activation of a larger number of motor units. The diminution in turns was more marked when the force was $30 \%$ of maximum than during maximum and $10 \%$ of maximum effort. In normal muscle the number of turns during maximum effort was lower than when the force was $30 \%$ of maximum, probably because of the synchronisation in firing of different motor units when most motor units discharge near their upper frequency limit (Adrian, 1947; Buchthal and Madsen, 1950).

None of the patients with neurogenic involvement showed the increase in turns that characterised myopathy (Willison, 1964; FuglsangFrederiksen et al., 1976). Conversely $20 \%$ of the patients with myopathy showed a 'false positive' decrease in turns. They would have been classified as 'neurogenic' had there not been other criteria 


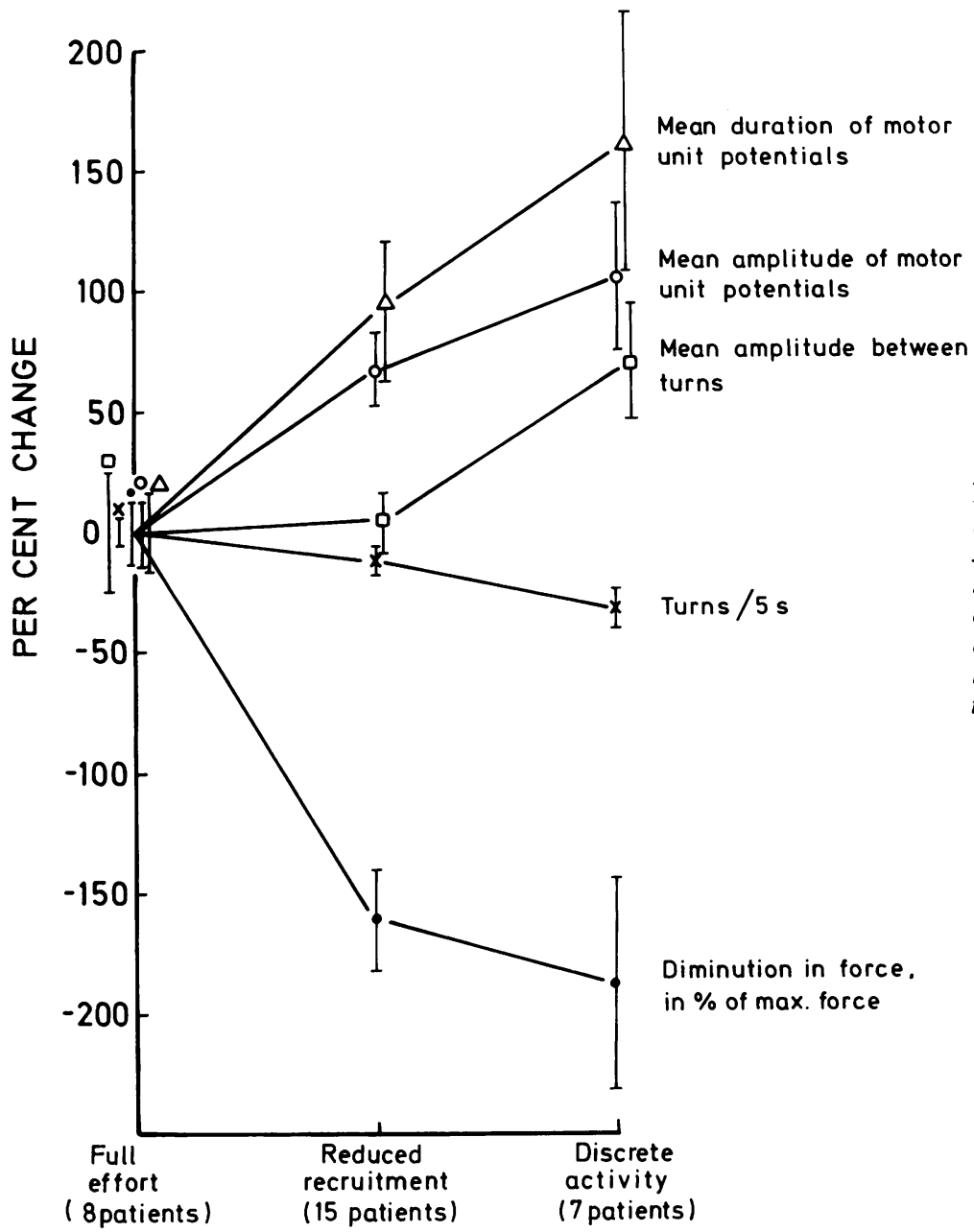

Fig. 7 Criteria of abnormality for the pattern of recruitment during $30 \%$ of maximum effort and for individual motor unit potentials as a function of the pattern of activity during full effort. The lowest curve shows the diminution in force as percentage of maximum. Vertical bars denote mean error.

indicating myopathy. Thus, most of these patients showed an increase of the ratio of turns to amplitude between turns. Patients with neurogenic involvement, in whom the number of turns was diminished, usually also showed an increase in the incidence of long time intervals that did not occur in myopathy. The ratio of turns to amplitude, the most sensitive criterion of myopathy, did not give additional information above that obtained from the decrease in turns in patients with neurogenic involvement. The ratio of turns to amplitude is largely independent of force and hence of the loss of motor units that characterised neurogenic involvement (Fuglsang-Frederiksen et al., 1976).

Experiments in which the duration of motor unit potentials was prolonged by cooling the muscle indicated that the diminution in the number of turns in muscles with neurogenic involvement was mainly due to the prolonged duration of the individual motor unit potentials. The effect of the loss of motor units on the number of turns was half that of the increase in duration. The decrease in the number of turns due to the increase in mean duration of motor unit potentials and to the loss of motor units would have been more marked had it not been counteracted by the increased incidence of polyphasic potentials. Thus, an average increase in mean duration of $54 \%$ would cause a decrease in the number of turns of $65 \%$; an average diminution in force of $60 \%$ would cause a decrease in the number of turns of $36 \%$. In fact, the decrease in turns averaged only 


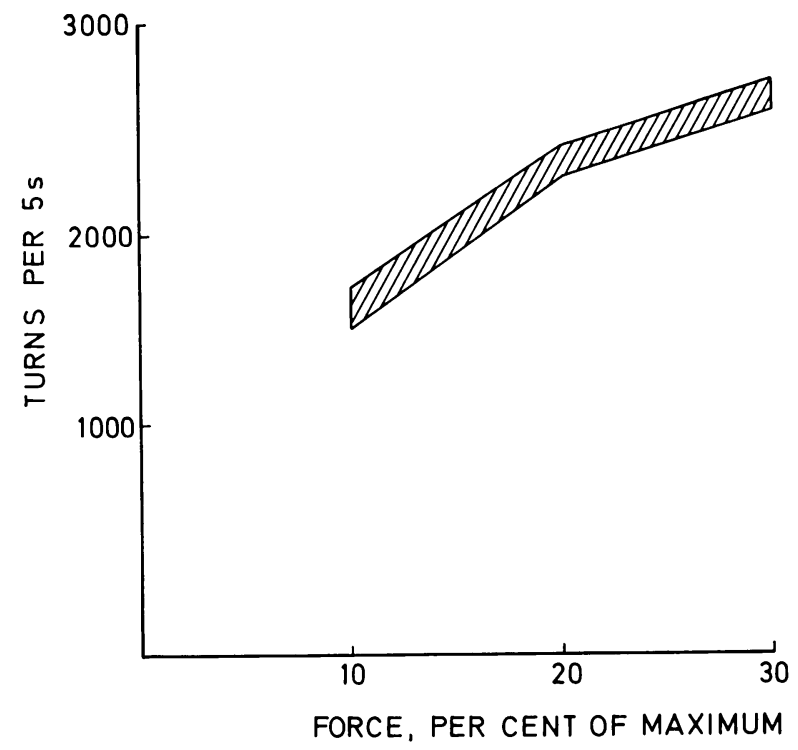

Fig. 8 Turns per 5 s at 10,20 , and $30 \%$ of maximum force (see Methods). Hatched area indicates the scatter ( \pm mean error).

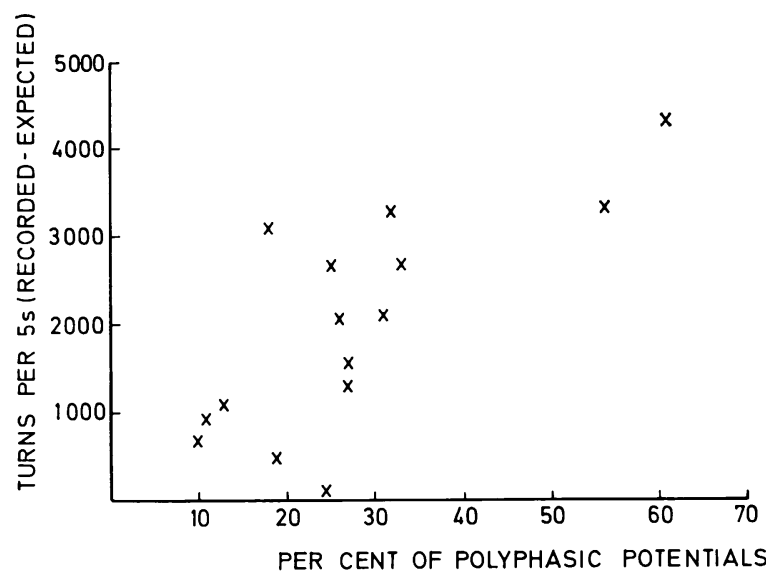

Fig. 9 Number of turns per $5 s$ to be expected from the incidence of polyphasic potentials in the brachial biceps and brachialis muscles of 15 patients with a lesion of the brachial plexus. Ordinate represents difference between number of turns recorded and number of turns to be expected from the increased mean duration and the diminished force (due to loss of motor units $)(y=63 x+225 ; S D 798 ; P<0.01)$.

$26 \%$, the difference from the expected decrease being due to the increased incidence of polyphasic potentials (on the average $28 \%$ ).

The work was supported by a grant from the Muscular Dystrophy Association of America, New York, and the Michaelsen Foundation, Copenhagen. We thank Dr W. Trojaborg for permission to use his electromyographical findings in patients with a lesion of the brachial plexus, and $\mathrm{Mr} \mathrm{K}$. Dahl for technical assistance. We are indebted to the late Dr P. Rosenfalck, Copenhagen, and to Dr R. G. Willison, London, for helpful suggestions in the preparation of the manuscript.

\section{References}

Adrian, E. D. (1947). General principles of nervous activity. Brain, 70, 1-17.

Bentsen, K. G. (1945). Single potentials from human muscles during fatigue, anoxia and temperature variations. Nordisk Medicin, 25, 697.

Buchthal, F. (1957). An Introduction to Electromyography, p. 43. Gyldendal: Copenhagen.

Buchthal, F., and Madsen, A. (1950). Synchronous activity in normal and atrophic muscles. Electroencephalography and Clinical Neurophysiology, 2, 425-444.

Dowling, M. H., Fitch, P., and Willison, R. G. (1968). A special purpose digital computer (Biomac 500) used in the analysis of the human electromyo- 
gram. Electroencephalography and Clinical Neurophysiology, 25, 570-573.

Fuglsang-Frederiksen, A., and Månsson, A. (1975). Analysis of electrical activity of normal muscle in man at different degrees of voluntary effort. Journal of Neurology, Neurosurgery, and Psychiatry, 38, 683-694.

Fuglsang-Frederiksen, A., Scheel, U., and Buchthal, F. (1976). Diagnostic yield of analysis of the pattern of electrical activity and of individual motor unit potentials in myopathy. Journal of Neurology, Neurosurgery, and Psychiatry, 39, 742-750.

Hayward, M., and Willison, R. G. (1973). The recognition of myogenic and neurogenic lesions by quantitative EMG. In New Developments in Electromyography and Clinical Neurophysiology. Edited by J. E. Desmedt. Vol. 2, pp. 448-453. Karger: Basel.

Rose, A. L., and Willison, R. G. (1967). Quantitative electromyography using automatic analysis. Studies in healthy subjects and patients with primary muscle disease. Journal of Neurology, Neurosurgery, and Psychiatry, 30, 403-410.

Willison, R. G. (1964). Analysis of electrical activity in healthy and dystrophic muscle in man. Journal of Neurology, Neurosurgery, and Psychiatry, 27, 386-394. 